\title{
The Diagnosis of Chronic Obstructive Pulmonary Disease
}

Rainer Burkhardt, Wulf Pankow

\section{SUMMARY}

Background: Estimates of the prevalence of chronic obstructive pulmonary disease (COPD) in Germany range from $1.9 \%$ to $13.2 \%$, depending on the population studied and the investigative methods used. About $30 \%$ of all patients already have severe airway obstruction by the time the condition is diagnosed.

Methods: Review of pertinent literature retrieved by a selective search, including current guidelines and textbooks.

Results: Smoking is the main risk factor for COPD. The diagnosis is based on characteristic symptoms that patients at risk should be actively asked about—cough, dyspnea, diminished physical reserve, and frequent airway infections-together with abnormal pulmonary function tests. Spirometry usually suffices to document impaired air flow. The clinical evaluation and the treatment strategy are based on the severity of airway obstruction and dyspnea, and the frequency of exacerbations. According to a European study, dyspnea is present in $73 \%$ of persons with severe COPD, expectoration in $64 \%$, cough in $59 \%$, and wheezing in $42 \%$. Asthma, congestive heart failure, and interstitial lung disease are the main differential diagnoses.

Conclusion: COPD may begin with symptoms that are only mild at first even in a longstanding smoker. The available diagnostic techniques need better prospective validation with respect to relevant endpoints, including mortality, symptom progression, quality of life, and frequency of exacerbations.

\section{Cite this as:}

Burkhardt R, Pankow W: The diagnosis of chronic obstructive pulmonary disease. Dtsch Arztebl Int 2014; 111: 834-46. D0I: 10.3238/arztebl.2014.0834
A mong all chronic diseases of the lungs, chronic obstructive pulmonary disease (COPD) has the highest mortality worldwide (1) and also accounts for the greatest number of years lived with disability (2). In the official German cause-of-death statistics, COPD (ICD-10 code J44.-) took $9^{\text {th }}$ place in 1998 , just after lung cancer; by 2012, it had risen to $5^{\text {th }}$ place, with 26654 deaths in that year (e1).

The term COPD arose historically from the fusion of two disease entities that were previously considered separate: pulmonary emphysema and chronic (obstructive) bronchitis. These two conditions were combined in a single, clinically and functionally defined entity because they are often present simultaneously and cannot be satisfactorily distinguished from another on clinical grounds $(3,4)$. The characteristic clinical features of COPD are respiratory symptoms such as cough or dyspnea in association with a pharmacologically irreversible, or minimally reversible, airway obstruction that progresses over time (with a mean annual decline of 33-69 $\mathrm{mL}$ in forced expiratory volume in one second $\left.\left[\mathrm{FEV}_{1}\right]\right)(5$, e2). COPD is characterized by exacerbations, which tend to arise about once per year (6). Only $23 \%$ of all patients with moderate or severe obstruction remain free of exacerbations for three years (7).

It has often been observed that COPD is both underdiagnosed and usually diagnosed too late (8, e3). A desire to do better in these respects was one of the main reasons for the introduction of a Disease Management Program (DMP) for asthma and COPD in Germany in 2006/2007.

\section{Learning objectives}

In view of the fact that $80 \%$ of primary care physicians' offices are now equipped with spirometers, our purpose in writing this article is to improve physicians' understanding of

\section{Definition}

COPD is a functionally defined obstructive disease of the respiratory system that encompasses two previously separate entities: chronic obstructive bronchitis and pulmonary emphysema. 
- the typical history, symptoms, and signs of COPD,

- the pulmonary function studies that should be performed or ordered, and

- differential-diagnostic considerations with respect to physical findings and the results of pulmonary function tests.

The essential principles of the treatment of COPD are smoking cessation, anti-obstructive pharmacotherapy, physiotherapy, and exercise therapy. The reader is referred to the relevant guidelines for these matters (9-12). The German National Disease Management Guideline for COPD is now being updated (e4).

\section{Methods}

This review is based on pertinent literature retrieved by a selective search of PubMed with the search terms "chronic obstructive pulmonary disease" and "respiratory function tests," along with textbooks of diagnostic pulmonary function testing $(13,14)$ and current clinical guidelines (9-12). As there have been practically no controlled studies on the diagnostic evaluation of COPD, evidence levels are not mentioned here.

\section{Epidemiology}

The reported prevalence of COPD in Germany varies depending on age, smoking status, and the participation rates of the groups being studied, as well as the varying diagnostic criteria that are applied. In the international BOLD (Burden of Obstructive Lung Disease) Study of 2005, representative random samples of the population aged 40 and over were studied in 12 different locations around the world. In Germany, 683 persons living in Hannover were included in the study (participation rate: $28 \%$ ). With COPD defined by the spirometric GOLD (Global Initiative for Chronic Obstructive Lung Disease) criteria (Table 1), the prevalence of the condition was estimated at $13.2 \%$ (5.9\% for grade 2 to 4 COPD, $7.4 \%$ for grade 1 COPD) $(15$, e 5$)$. The prevalence of COPD was about twice as high in men as in women and rose with age and with the quantity of cigarette smoking (measured in pack-years, i.e., the number of cigarettes smoked per day divided by 20 and multiplied by the duration of smoking in years) (15).

A study conducted in primary care practices in 2007 on 432 smokers aged 40 and over, with a participation rate of $81 \%$, revealed a much lower prevalence of COPD: $6.9 \%$. Half of the patients

\section{TABLE 1}

\section{The severity of airway obstruction in COPD}

Condition: testing after bronchodilation and $\mathrm{FEV}_{1} / \mathrm{FVC}<0.7$

\begin{tabular}{l|l|l|l|} 
& 1 & mild & $\mathrm{FEV}_{1} \geq 80 \%$ predicted \\
\cline { 2 - 4 } $\mathcal{\mathrm { O }} \mathrm{\mathcal {O }}$ & 2 & moderate & $50 \% \leq \mathrm{FEV}_{1}<80 \%$ predicted \\
\cline { 2 - 4 } & 3 & severe & $30 \% \leq \mathrm{FEV}_{1}<50 \%$ predicted \\
\hline 4 & very severe & $\begin{array}{l}\mathrm{FEV}_{1}<30 \% \text { predicted (until } 2011 \text {, also } \mathrm{FEV}_{1}<50 \% \\
\text { and chronic hypoxemia with } \mathrm{PaO}_{2}<60 \mathrm{~mm} \mathrm{Hg} \text { ) }\end{array}$
\end{tabular}

\begin{tabular}{|c|c|c|c|}
\hline \multirow{6}{*}{ 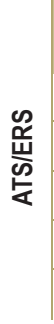 } & \multicolumn{3}{|c|}{$\begin{array}{l}\text { Condition: Tiffeneau Index below } 5^{\text {th }} \text { percentile for normalized distribution } \\
\text { (LLN) }\end{array}$} \\
\hline & 1 & mild & $\mathrm{FEV}_{1} \geq 70 \%$ predicted \\
\hline & 2 & moderate & $\mathrm{FEV}_{1} 60-69 \%$ predicted \\
\hline & 3 & moderate to severe & $\mathrm{FEV}_{1} 50-59 \%$ predicted \\
\hline & 4 & severe & $\mathrm{FEV}_{1} 35-49 \%$ predicted \\
\hline & 5 & very severe & $\mathrm{FEV}_{1}<35 \%$ predicted \\
\hline
\end{tabular}

Classification of severity of airway obstruction in COPD according to GOLD and ATS/ERS (e28). The GOLD recommendation exclusively concerns COPD, while the ATS/ERS classification can be used for spirometric findings in general.

GOLD, Global Initiative for Chronic Obstructive Lung Disease; ATS, American Thoracic Society; ERS, European Respiratory Society; $\mathrm{FEV}_{1}$, forced expiratory volume in one second; FVC, forced vital capacity; LLN, lower limit of normal

found to have COPD in this study had not previously been given the diagnosis (e6).

In a study of 1809 volunteers from among the 3300 participants of the Study of Health in Pomerania (SHIP) (age range: 25-85), carried out in the period 2003-2006, the prevalence of COPD was either $1.9 \%$ or $6.7 \%$, depending on the spirometric criterion used to define it (a fixed threshold for relative onesecond capacity set at 0.7 in the GOLD scheme, versus the lower limit of the normal range derived from the study data [e7]).

\section{Etiology}

Inhaled cigarette smoke is the main risk factor for COPD in the Western world (15). In the German Adult Health Study (Studie zur Gesundheit Erwachsener in Deutschland), carried out from 2008 to 2011 , the percentage of smokers among persons aged 18 to 79 was $29.7 \%$ (26.9\% for women and $32.6 \%$ for men; one in five smokers of either sex were only occasional smokers [e8]). In a cohort study from Copenhagen, $20.7 \%$ of persons aged 30 to 60 with

\section{Epidemiology}

Chronic obstructive pulmonary disease (COPD) is the fifth most common cause of death in Germany.

\section{Risk factors}

The most important risk factor for COPD is cigarette smoking. 
FIGURE 1

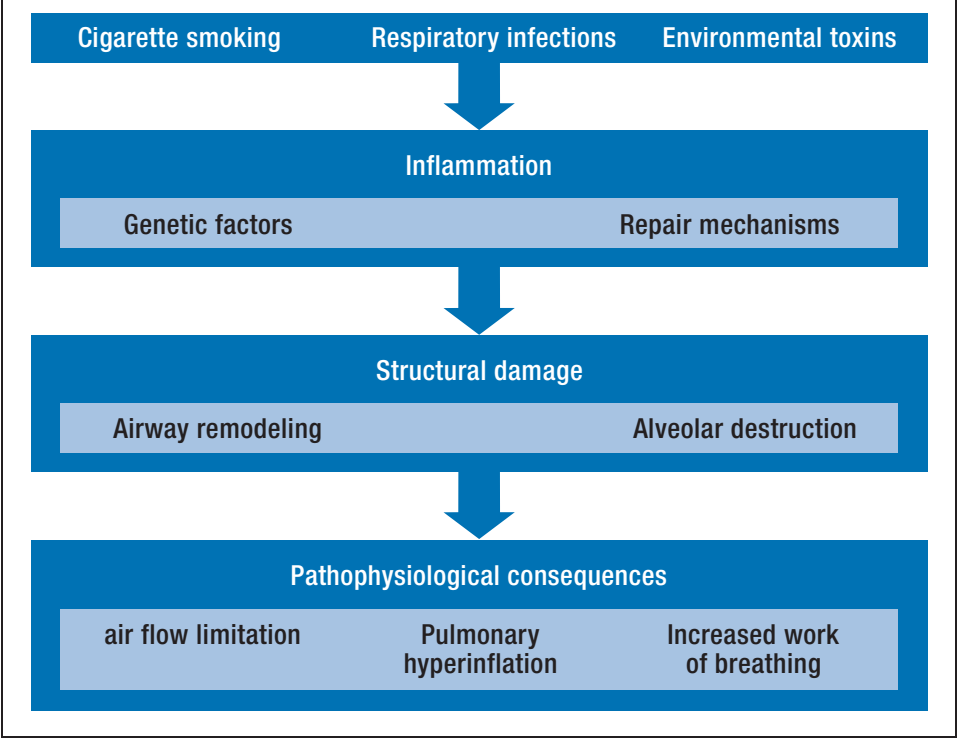

Diagram of the pathogenesis and pathophysiology of COPD, created by the authors on the basis of the articles by Hogg et al. (20) and Tuder and Petrache (e26).

COPD, chronic obstructive pulmonary disease normal pulmonary function at baseline who were continually active smokers developed at least moderate COPD over 25 years of follow-up, compared to $3.6 \%$ of persons who never smoked (e9). Epidemiologic studies have shown that only about $5 \%$ of adults who have never smoked have COPD (16). It should be borne in mind, however, that many epidemiologic studies cannot reliably distinguish asthma from COPD because they are based exclusively on pulmonary function tests, often without any bronchodilator reversibility testing being performed.

The risk factors for COPD in nonsmokers include asthma (e10), advanced age, low educational level, occupational exposure to toxins, and a history of airway infections in childhood (17). COPD in persons who have never smoked has different features from COPD in current and former smokers, with a generally more favorable course (18). Around the world, biomass combustion for domestic cooking and heating, and the ensuing pollution of household air, are an important cause of COPD (19). The role of general air pollution remains unclear; its acute effects on pulmonary function have yet to be adequately separated from any chronic damage that it might produce (e11).

\section{Pathogenesis}

Airway obstruction in COPD results from changes in the airways and in the pulmonary parenchyma (Figure 1). Both components of the disease (bronchitis/ bronchiolitis and emphysema) contribute to its clinical symptoms and signs and to the limitation of expiratory flow that is demonstrated by pulmonary function testing (20). In healthy individuals, the elasticity of lung tissue normally keeps the non-cartilaginous airways open during expiration; in COPD, reduced elasticity, along with airway narrowing due to inflammation, causes an increase in airway resistance and a displacement of its main component from the large bronchi to the small airways (14).

\section{Symptoms and signs}

The clinical manifestations of COPD include dyspnea, chronic cough (productive or non-productive), low exercise capacity, audible wheezing, and more frequent or longer-lasting bronchial infections; a further manifestation of advanced COPD is weight loss (10). The appearance of at least one of these

\section{Risk factors in nonsmokers}

The risk factors for COPD in nonsmokers include asthma, advanced age, low educational level, occupational exposure to noxious agents, and a history of airway infections in childhood.

\section{Limitation of expiratory flow}

In COPD, expiratory flow is limited by the diminished available cross-sectional area of the small airways and by reduced elasticity of lung tissue. 
manifestations in the presence of a risk factor (usually cigarette smoking) should arouse the suspicion of COPD (10). The 7-day prevalence of individual manifestations of COPD among patients in GOLD stages 3 and 4 was determined in a multinational European study (21) (Table 2). The disease manifestations usually progress slowly. Persons who take little exercise to begin with can often tolerate a marked restriction of their pulmonary function without any symptoms whatsoever; others avoid shortness of breath by becoming less physically active (22). In a study from New Mexico, 31\% of patients with COPD already had severe airway obstruction (GOLD 3 or 4 ) at the time of diagnosis (e12).

Patients describe dyspnea variously as a feeling of not getting enough air, of increased effort in inspiration or expiration, or of tightness in the chest. Dyspnea can arise during physical activity, while the patient is speaking, or at rest. The patient's smoking history should be quantified in pack-years, or at least in years as a smoker (23).

\section{Physical examination}

The physical examination serves to provide further evidence of COPD, to detect accompanying conditions, and to rule out the most important differential diagnoses (23). Inspection may reveal abnormalities of the thoracic skeleton, e.g., kyphoscoliosis. Percussion and auscultation may yield evidence of left heart failure or a pleural effusion (23).

Continuous or musical adventitious lung sounds ("wheezes" and "rhonchi"; acoustic examples are available online [24]) are characteristic findings but are not invariably present. They arise from airway narrowing and mucous coating and are also heard in asthma attacks (25).

Diminished normal ("vesicular") breathing sounds and increased resonance to percussion tend to be heard in more advanced COPD (e13).

Discontinuous adventitious lung sounds (crackles, previously known as rales) are characteristic of pulmonary fibrosis and of pulmonary congestion due to left heart failure; coarser crackles are sometimes heard in COPD with a bronchitic component (25). In very advanced COPD, or during a severe exacerbation, patients may have orthopnea, and the use of accessory muscles of respiration at rest may be seen (23).

\section{Hyperinflation of the lungs}

The static component of pulmonary hyperinflation is due to the loss of elasticity in emphysematous lung tissue.

\section{FIGURE 2}

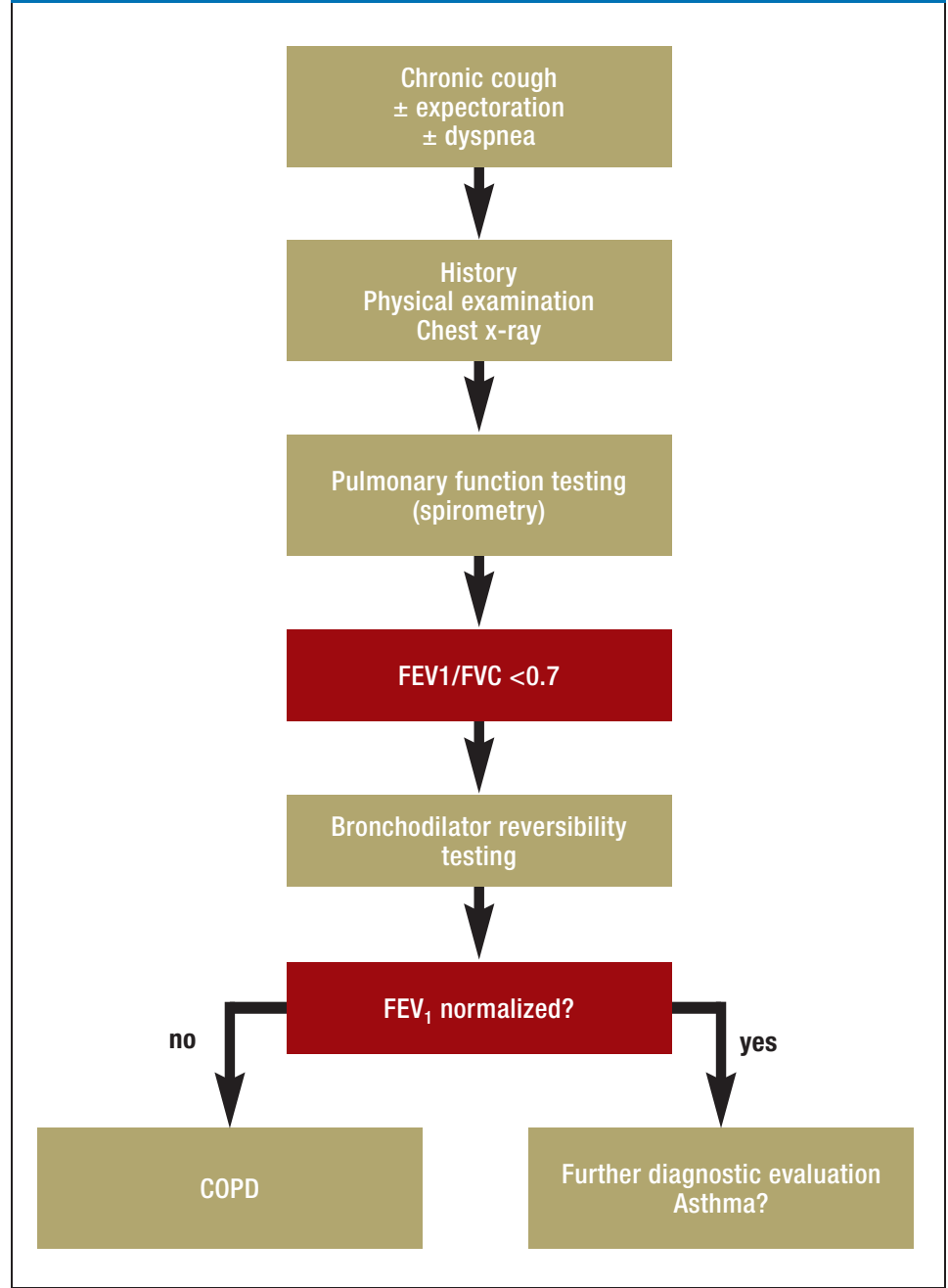

Diagnostic algorithm for COPD, after Vogelmeier et al (12). COPD, chronic obstructive pulmonary disease; FVC, forced vital capacity; FEV $_{1}$, forced expiratory volume in one second

\section{The symptoms and signs of COPD}

These include dyspnea, chronic cough (productive or not), low exercise capacity, audible wheezing, more frequent or longerlasting bronchial infections, and, in advanced COPD, weight loss. 


\section{FIGURE 3}

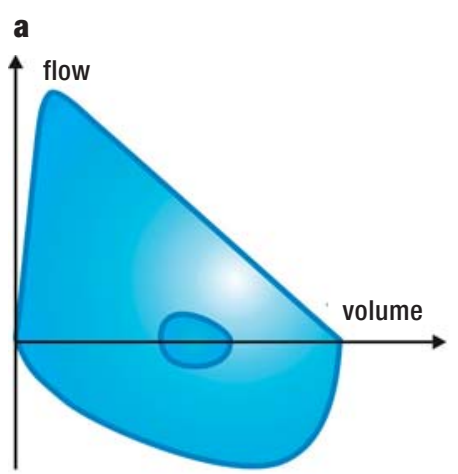

\section{b}

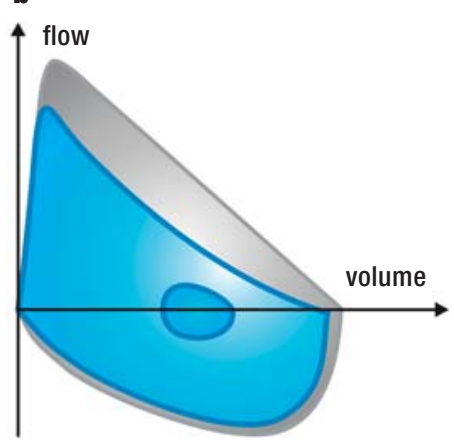

c

$\uparrow$ flow

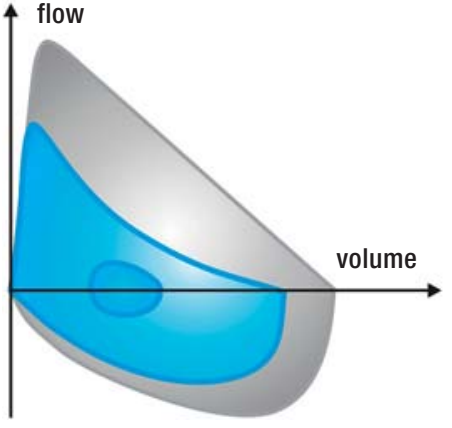

d

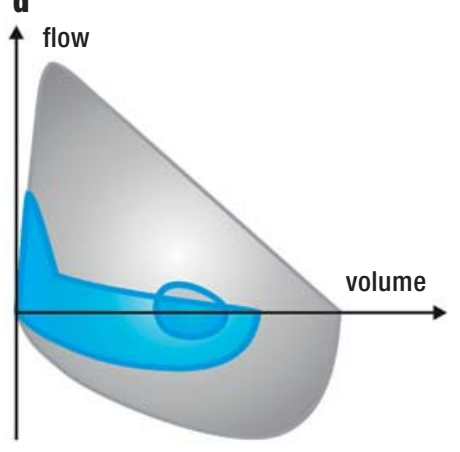

Ideal flow-volume curves for breathing at rest (smaller loop) and a forced maneuver (larger loop), with inspiration below and expiration above, the total lung capacity (TLC) indicated at left, and the residual volume (RV) at right on the volume axis.

a) Normal; b) mild obstruction; c) moderate obstruction with reduced FVC (forced vital capacity) and shift of respiration at rest toward inspiration; d) severe obstruction with limitation of expiratory flow at rest. In b)-d), the normal curve is shown in gray in the background. The expiratory portion of the curve becomes more concave with increasing obstruction. Diagram: H.-J. Smith

\section{BOX}

\section{Diagnostic tests that are not a part of the routine evaluation for suspected COPD}

- Computed tomography (CT) of the chest to show emphysema

- Magnetic resonance imaging (MRI) of the chest (39)

- Allergy testing without any history suggesting allergic asthma

- Nitric oxide measurement in expired air (FeNO)

- Pulse oximetry for exertional desaturation

\section{Smoking behavior}

The patient's smoking history should be quantified in pack-years, or at least in years as a smoker.

\section{Ancillary diagnostic testing}

The history and physical findings are not specific; only extreme symptoms and signs have a high positive predictive value (e.g., more than 55 years of smoking, accompanied by wheezing that can be heard both by the patient and by the doctor [e14]). Therefore, airway obstruction must be documented with pulmonary function testing to confirm the diagnosis of COPD securely (Figure 2) (11). Other types of ancillary diagnostic testing serve mainly to rule out competing differential diagnoses (10).

A chest $x$-ray in two planes is an obligate part of the initial evaluation. It helps rule out the following differential diagnoses:

- congestive heart failure

- pleural effusion

- interstitial lung disease

- tumor of the lung (10).

An electrocardiogram (ECG) should also be obtained in the initial evaluation (12). According to the Copenhagen City Heart Study, many patients with COPD also have coronary heart disease: $14.6 \%$ of those in GOLD stage 2, and $16.3 \%$ of those in GOLD stages 3 and 4 (e15). An echocardiogram should be obtained if cor pulmonale is suspected, or if there is any evidence of left heart failure (10).

An arterial blood-gas analysis is obligatory only in severe cases of COPD or in patients with polycythemia or cor pulmonale (12). It is also recommended for patients whose oxygen saturation level in pulse oximetry is below $92 \%(10)$.

A complete blood count serves to exclude anemia as a possible cause of dyspnea in the differential diagnosis of COPD (10). For patients under age 65 who have smoked less than 20 pack-years, testing for alpha-1-antitrypsin deficiency is recommended, as this is a potential genetic cause of COPD (26). Diagnostic tests that are not recommended as a part of routine evaluation are summarized in the Box.

\section{Pulmonary function tests as a screening method?}

The spirometric screening of asymptomatic persons at risk, e.g., smokers over age 40 , has been a topic of discussion but is not recommended in the current guidelines (e16). An ongoing controlled trial is now being addressed to the important question whether patients' knowledge of their pulmonary function values might increase their willingness to quit 


\section{FIGURE 4}

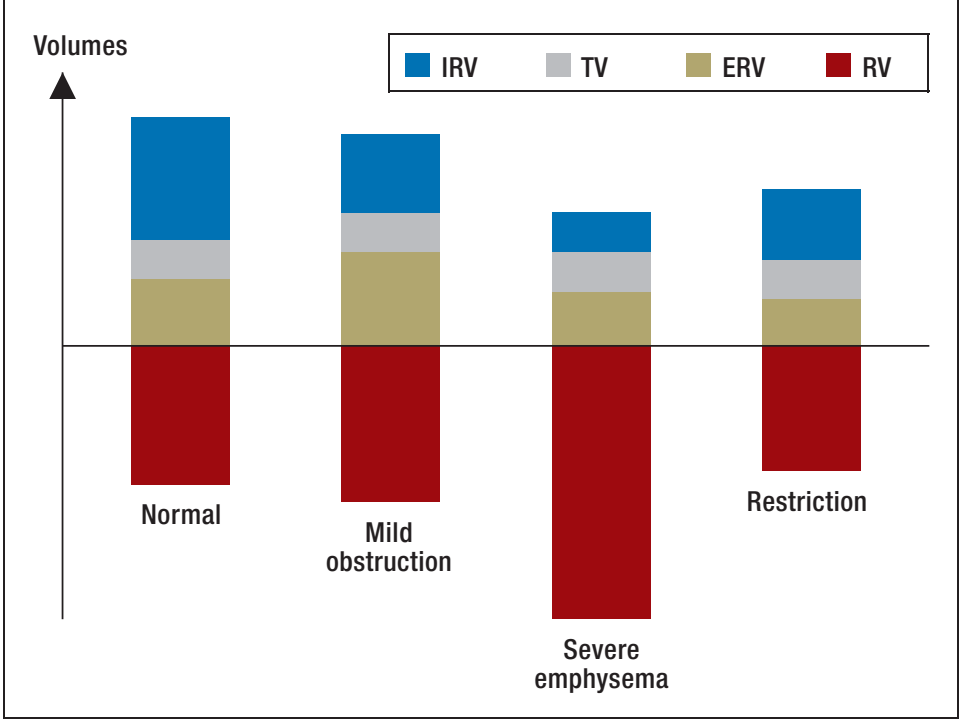

Static lung volumes.

The portions above the horizontal line can

also be measured by spirometry.

IRV, inspiratory reserve volume

TV, tidal volume

ERV, expiratory reserve volume

$\mathrm{RV}$, residual volume.

Inspiratory capacity $(\mathrm{IC})=\mathrm{IRV}+\mathrm{TV}$

Vital capacity $(V C)=I R V+T V+E R V$

Functional residual capacity $(F R C)=E R V+R V$

Total capacity $(T L C)=V C+R V$, corresponding to

the total height of the column.

Note the similarity of the spirometrically

measured volumes in restrictive disease and

emphysema smoking (e17). The early diagnosis of COPD in asymptomatic persons would give many such persons a diagnostic label and possibly expose them to unnecessary drug treatment despite their low risk of future complications of COPD (e18).

On the other hand, heightened attention to patients' symptoms and a greater readiness to proceed to spirometry are advisable in patients who seem likely to be able to tolerate a mild degree of impairment without complaint. If further investigation yields no indication for drug treatment, the patient should be advised to quit smoking and to have annual influenza vaccinations and a single vaccination against pneumococci.

\section{Spirometry}

The diagnostic algorithm for pulmonary function testing in suspected COPD begins with spirometry $(3,9-12)$, the most sensitive way to detect airway obstruction. The patient performs a calm, maximal inspiration followed by a forced expiration; the expired volume of air in one second (forced expiratory volume in one second, $\mathrm{FEV}_{1}$ ) and the total expired volume (forced expiratory vital capacity, FVC) are measured. This test relies on the patient's cooperation. It must be administered by well-trained and motivated personnel in accordance with accepted standards; under these conditions, the findings can be considered reliable. In $90 \%$ of patients with COPD, two consecutive tests at short intervals yield consistent $\mathrm{FEV}_{1}$ values, with a difference of less than $225 \mathrm{~mL}$ between them (e19).

The respiratory maneuver described above is performed repeatedly (usually three times). Good reproducibility can be assumed if the values obtained for maximal expiratory flow cannot be increased any further by intense effort. The agreement of the two best measured values (the highest sum of FVC and $\mathrm{FEV}_{1}$ ) should be documented within a defined range (the difference between the two best values of $\mathrm{FEV}_{1}$ and FVC should not exceed $150 \mathrm{~mL})(27,28)$. The result of the forced-expiration test can be depicted as a flow-volume curve (Figure $3 a$ ). A detailed description of how this test is performed and how its quality can be assessed is found in the e-Supplement to this article.

\section{Diagnostic criteria}

Spirometry generally suffices to demonstrate an abnormally low expiratory flow in patients with COPD (29). The most reliable criterion for airway obstruction is the ratio of $\mathrm{FEV}_{1}$ to vital capacity;

\section{Pulmonary function testing}

The diagnostic algorithm for pulmonary function testing in suspected COPD begins with spirometry.

\section{Prerequisites for spirometry}

This test relies on the patient's cooperation. It must be administered by well-trained and motivated personnel in accordance with accepted standards. 


\section{FIGURE 5}
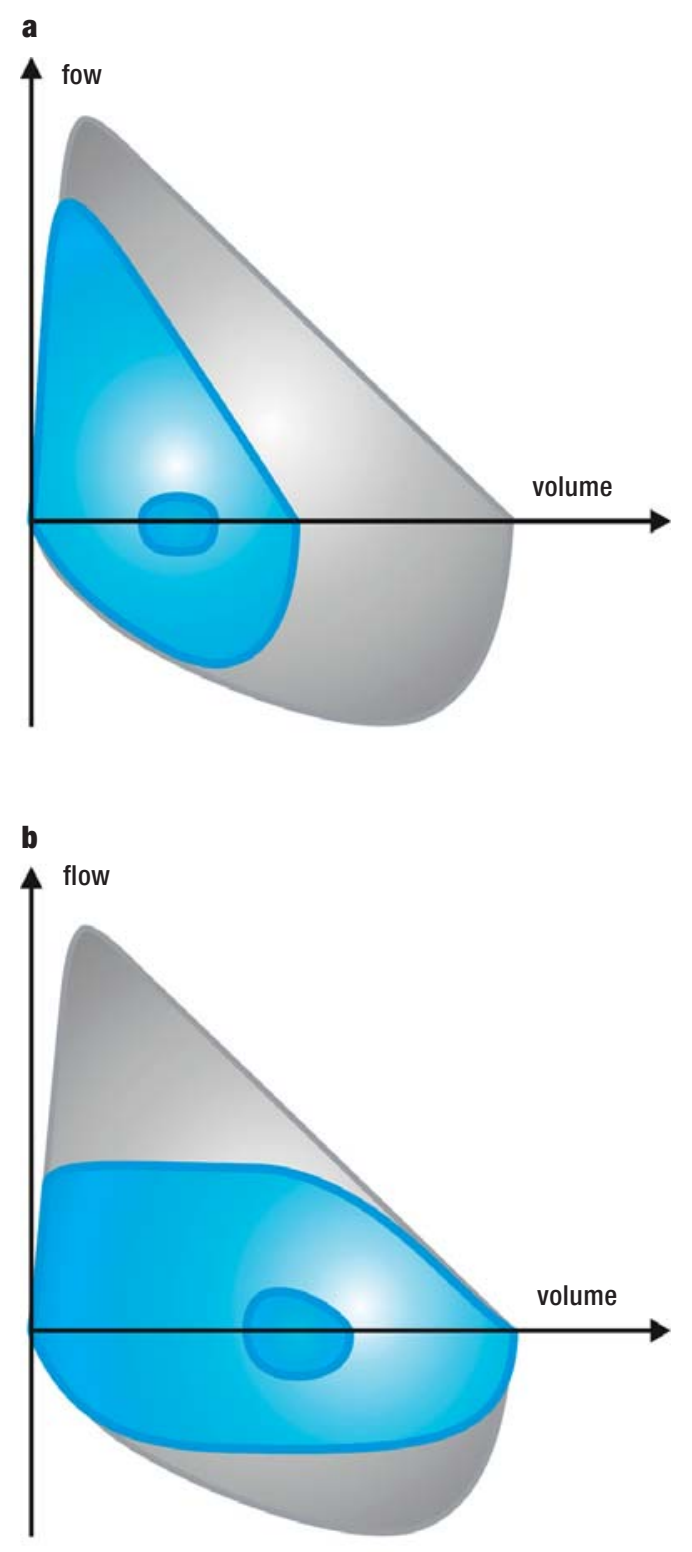

Abnormal flow-volume curves superimposed on a normal curve (gray, background):

a) reduced IVC (inspiratory vital capacity) and FVC

(forced expiratory vital capacity) with normal flow values, indicating a restrictive ventilatory impairment;

b) reduced inspiratory and/or expiratory flow values, indicating stenosis of major airways. Diagram: H.-J. Smith according to the GOLD recommendations, vital capacity should be estimated by the FVC in the same respiratory maneuver from which the $\mathrm{FEV}_{1}$ was obtained (9).

Patients with COPD may be unable to expire fully in a forced maneuver because of premature bronchiolar collapse ("air trapping"); therefore, the vital capacity is additionally measured in an unforced, "slow" inspiratory maneuver (10). To distinguish it from the FVC, the vital capacity measured in this way is called the inspiratory vital capacity (abbreviated most correctly as IVC, often shortened to VC). In Germany, the FEV1/IVC ratio is referrred to as the Tiffeneau Index or the relative expiratory capacity in one second (27). For practical purposes, the highest measured value of the vital capacity $\left(\mathrm{VC}_{\max }\right)$ can be used to compute this ratio (29).

Pulmonary function testing after the administration of a bronchodilator is recommended for the diagnosis and staging of COPD and for the assessment of its course. Such testing yields more reproducible results, enables more secure differentiation of COPD from asthma, and obviates the need to interrupt drug treatment in patients who are already being treated $(10,11)$.

\section{What is normal?}

Controversy still surrounds the question of what threshold value should be used to define a pathological degree of airway obstruction. The GOLD recommendation is that airway obstruction should be diagnosed if the $\mathrm{FEV}_{1} / \mathrm{FVC}$ quotient is below 0.7 (9). This recommendation takes no account of the fact that all pulmonary function values, including this quotient, normally vary as a function of the patient's age, sex, height, and ethnic origin.

The range of normal is often defined as the range in which $95 \%$ of normal subjects are found (e20). A fixed threshold of 0.7 , in contrast, leads to a falsepositive diagnosis of airway obstruction in $25-60 \%$ of persons in their seventh decade (30). Meanwhile, it led to a false-negative diagnosis of no airway obstruction in $5.1 \%$ of the subjects in the European Community Respiratory Health Survey, who were 20 to 44 years old (31).

New prediction equations for normal values and their standard deviations were recently derived from pulmonary function tests carried out on more than 75000 healthy individuals of diverse ethnic origins.

\section{Interpretation}

The $\mathrm{FEV}_{1} / \mathrm{IVC}$ ratio (also called the Tiffeneau Index in Germany), is the main criterion for airway obstruction.

\section{Normal limits}

For the diagnosis of COPD, concordant clinical symptoms and test findings are more important than statistical "normality," which defines $5 \%$ of healthy persons as abnormal. 


\section{Synoptic chart of clinical manifestations and findings}

\begin{tabular}{|c|c|c|c|c|c|c|}
\hline & $\begin{array}{l}\text { Grade 1-2 }(-3) \\
\text { COPD }\end{array}$ & $\begin{array}{l}\text { Grade } 4 \text { COPD } \\
\text { (with emphysema) }\end{array}$ & Asthma & $\begin{array}{l}\text { Interstitial lung } \\
\text { disease }\end{array}$ & $\begin{array}{l}\text { Congestive } \\
\text { heart failure }\end{array}$ & Obesity \\
\hline Symptoms & $\begin{array}{l}\text { Cough, expectora- } \\
\text { tion, dyspnea }\end{array}$ & $\begin{array}{l}\text { Dyspnea, cough, } \\
\text { expectoration }\end{array}$ & Dyspnea episodes & Dyspnea, cough & $\begin{array}{l}\text { Dyspnea, } \\
\text { orthopnea, edema }\end{array}$ & Dyspnea \\
\hline History & $\begin{array}{l}\text { Smoker, onset of } \\
\text { symptoms after age } \\
40\end{array}$ & $\begin{array}{l}\text { Smoker, onset of } \\
\text { symptoms after age } \\
40\end{array}$ & $\begin{array}{l}\text { Allergies, onset of } \\
\text { symptoms often } \\
\text { before age } 30\end{array}$ & $\begin{array}{l}\text { Organic or inorganic } \\
\text { dusts, adverse drug } \\
\text { effect, collagenosis }\end{array}$ & $\begin{array}{l}\text { Underlying cardiac } \\
\text { disease }\end{array}$ & \\
\hline Physical findings & $\begin{array}{l}\text { Normal or con- } \\
\text { tinuous adventitious } \\
\text { lung sounds }\end{array}$ & $\begin{array}{l}\text { Low volume of } \\
\text { breathing sounds, } \\
\text { hypersonority to per- } \\
\text { cussion, continuous } \\
\text { adventitious lung } \\
\text { sounds }\end{array}$ & $\begin{array}{l}\text { Only during episode: } \\
\text { continuous adventi- } \\
\text { tious lung sounds }\end{array}$ & $\begin{array}{l}\text { Discontinuous } \\
\text { adventitious lung } \\
\text { sounds }\end{array}$ & $\begin{array}{l}\text { Discontinuous } \\
\text { adventitious lung } \\
\text { sounds }\end{array}$ & $\begin{array}{l}\text { BMl usually } \\
>40 \mathrm{~kg} / \mathrm{m}^{2}\end{array}$ \\
\hline Chest x-ray & Normal & $\begin{array}{l}\text { Low diaphragm, } \\
\text { attenuation of pul- } \\
\text { monary margins }\end{array}$ & Normal & $\begin{array}{l}\text { Reticular or reticulo- } \\
\text { nodular infiltrates }\end{array}$ & $\begin{array}{l}\text { Enhanced } \\
\text { pulmonary vessels, } \\
\text { cardiomegaly }\end{array}$ & High diaphragm \\
\hline Spirometry & $\begin{array}{l}\mathrm{FEV}_{1} / \mathrm{FVC}<\mathrm{LLN} \text { or } \\
<0.7\end{array}$ & $\begin{array}{l}\mathrm{FEV}_{1} / \mathrm{FVC}<\mathrm{FLN} \text { or } \\
<0.7, \mathrm{FEV}, \text { below } \\
35 \% \text { predicted, } \mathrm{VC} \\
\text { and } \mathrm{FVC} \text { abnormally } \\
\text { low }\end{array}$ & $\begin{array}{l}\text { FEV } 1 \text { low with } \\
\text { (near-) normalization } \\
\text { after bronchial spas- } \\
\text { molysis; normal } \\
\text { findings between } \\
\text { episodes }\end{array}$ & $\begin{array}{l}\text { VC and FVC re- } \\
\text { duced, FEV } 1 / F V C \\
>\text { LLN or }>0.7\end{array}$ & $\begin{array}{l}\text { Normal, with pos- } \\
\text { sible reduction of VC } \\
\text { and FVC }\end{array}$ & $\begin{array}{l}\text { VC and FVC re- } \\
\text { duced, } F E V_{1} / F V C \\
>L L N \text { or }>0.7\end{array}$ \\
\hline $\begin{array}{l}\text { Static volumes } \\
\text { (body plethysmog- } \\
\text { raphy) }\end{array}$ & $\begin{array}{l}\text { Normal or mildly } \\
\text { increased RV }\end{array}$ & $\begin{array}{l}\text { Markedly increased } \\
\mathrm{RV}\end{array}$ & Normal & Low TLC & Normal & Low TLC \\
\hline $\begin{array}{l}\text { Further pulmonary } \\
\text { function tests }\end{array}$ & $\begin{array}{l}\text { Airway resistance } \\
\text { may be increased }\end{array}$ & $\begin{array}{l}\text { Reduced diffusion } \\
\text { capacity }\end{array}$ & $\begin{array}{l}\text { Bronchial provo- } \\
\text { cation test positive, } \\
\text { PEF variable }\end{array}$ & $\begin{array}{l}\text { Reduced diffusion } \\
\text { capacity }\end{array}$ & Normal & $\begin{array}{l}\text { Normal diffusion } \\
\text { capacity }\end{array}$ \\
\hline Blood gases & $\begin{array}{l}\text { Hypoxemia may be } \\
\text { seen }\end{array}$ & $\begin{array}{l}\text { Hypoxemia; hyper- } \\
\text { capnia may also be } \\
\text { seen }\end{array}$ & $\begin{array}{l}\text { Hypoxemia during } \\
\text { episodes; hypercap- } \\
\text { nia as well in status } \\
\text { asthmaticus }\end{array}$ & Hypoxemia & $\begin{array}{l}\text { Hypoxemia and } \\
\text { acidosis possible in } \\
\text { severe, acute } \\
\text { decompensation }\end{array}$ & Normal \\
\hline
\end{tabular}

Simplified synoptic chart of typical clinical manifestations and findings of the most common diseases causing dyspnea. The features listed are neither invariably present nor sufficient for

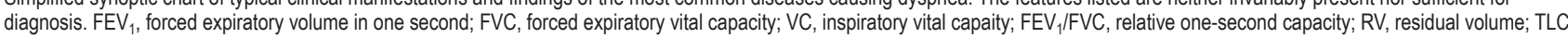
total lung capacity; PEF, peak expiratory flow; LLN, lower limit of normal. This chart was created in accordance with the authors' clinical experience and in the light of the pertinent specialized literature, especially $(13,40$, e27)

The use of these values is expected to lessen the risk of diagnostic error (32, e21).

For the diagnosis of COPD, the correlation between the clinical symptoms on the one hand and the findings of pulmonary function tests on the other is more important than the statistically defined threshold of normality; after all, $5 \%$ of healthy individuals will also have values under this threshold. Conversely - in view of the considerable intraindividual variability of measured values-supposedly normal findings that are just above the threshold value do not rule out the diagnosis of COPD once the relevant differential diagnoses have been duly investigated (e21).

Spirometry is generally viewed as a diagnostic gold standard. Consequently, its diagnostic validity (along with that of other tests, and the diagnostic threshold values of each) can only be judged in reference to external criteria. These include patient-relevant endpoints such as mortality, disease progression, quality of life, and frequency of exacerbations. More research is

\section{Differential diagnosis (1)}

Asthma is distinguished from COPD mainly on clinical grounds. The case history can help: the symptoms of asthma tend to arise in young persons.

\section{Differential diagnosis (2)}

A normalization of $\mathrm{FEV}_{1}$ or an increase by more than $400 \mathrm{~mL}$ in bronchodilator reversibility test supports the diagnosis of asthma. 
needed in this area. In particular, longitudinal studies would be helpful, as they would strengthen the evidence basis for evaluating the benefits and risks of currently available treatments (and those of future treatments) in each stage of COPD (33).

\section{Indications for expanded pulmonary function testing}

In patients with COPD, hyperinflation of the lungs (i.e., an increase of the residual volume that cannot be used for ventilation) is often a major contributory cause of dyspnea (34). The static component of pulmonary hyperinflation is due to loss of elasticity of the emphysematous pulmonary tissue (14). Hyperinflation is augmented by a shift of respiration at rest toward inspiration because of expiratory flow limitation. The latter phenomenon, called dynamic hyperinflation, initially arises during exercise and is later seen at rest as well. It facilitates the use of the remaining flow reserve but creates less favorable working conditions for the inspiratory musculature (e22).

The static lung volumes (Figure 4), including the residual volume, can be determined by body plethysmography. This measurement enables assessment of pulmonary hyperinflation (14). Expanded pulmonary function testing, performed by pulmonologists, is indicated if there is any residual uncertainty in the differential diagnosis, or if there is a discordance between the severity of dyspnea and the spirometric findings (e23). In addition to body plethysmography, a measurement of the diffusion capacity can also be helpful (10). It is low in emphysema because of the loss of lung parenchyma and the mismatch of ventilation and perfusion (14).

\section{Grading}

The $\mathrm{FEV}_{1}$, expressed as a percentage of the predicted value, is used to categorize the severity of airway obstruction (Table 1). In GOLD grade 1, and in mild obstruction as defined by the American Thoracic Society and the European Respiratory Society (ATS/ERS), the $\mathrm{FEV}_{1} / \mathrm{VC}$ ratio is low, but the $\mathrm{FEV}_{1}$ is still normal. A patient with a spirometric finding of this type can only be given the diagnosis of COPD if he or she has symptoms (10). Examples of typical flow-volume curves in COPD of various grades are shown in Figures $3 b$ to $3 d$.

The realization that other factors besides the degree of impairment of pulmonary function are of prognostic relevance in COPD has led to the development of complex indices (35). A simplified multidimentional staging of COPD (with stages A, B, $\mathrm{C}$, and $\mathrm{D}$ ) that takes dyspnea and the frequency of exacerbations into account, as well as the findings of pulmonary function tests, has been recommended by GOLD since 2011 (10). The clinical manifestations must be assessed for staging purposes with one of three recommended questionnaires. This concept has not become established in clinical practice, nor has it been demonstrated to date that A-B-C-D staging actually improves either the prognostication or the treatment of COPD (36). According to the current guidelines, treatment decisions should be based on the severity of airway obstruction, along with the clinical manifestations and the frequency of exacerbations (9-12).

\section{Differential diagnosis}

Asthma is distinguished from COPD mainly on clinical grounds. The case history can help: the symptoms of asthma tend to arise in young persons (although there are exceptions). Its course is typified by attacks of dyspnea with normal periods in between. The affected patients often have other allergic conditions affecting the skin and the upper airways. Patients with asthma often have normal spirometric findings during their asymptomatic intervals. Airway obstruction can be detected in such cases only by self-testing of pulmonary function (peak-flow protocol) or by bronchial provocation testing. If airway obstruction is present, bronchodilator reversibility testing can secure the diagnosis (Figure 2) (e24).

Before bronchodilator reversibility testing is performed, any bronchodilating drugs that the patient may be taking are temporarily withheld (short-acting preparations for 4 hours, longer-acting ones for 12 or 24 hours). For the test, spirometry is performed at baseline, a bronchodilating drug (preferably salbutamol) is given in a dose of four $100 \mu \mathrm{g}$ puffs at 30 -second intervals, and spirometry is repeated 10 to 15 minutes later (37). Normalization of $\mathrm{FEV}_{1}$ or an increase by more than $400 \mathrm{~mL}$ supports the diagnosis of asthma (10, e24). If spirometry reveals that the $\mathrm{FEV}_{1}$ and IVC (or FVC) are all lowered to roughly the same extent, with a flow-volume curve resembling a proportionally shrunken version of the normal curve, then a restrictive impairment of ventilation is the likely diagnosis (Figure $5 a$ ). The further evaluation of such a finding requires measurement of the total lung capacity (TLC) by body plethysmography or gas dilution (e23). If the

\section{Static lung volumes}

The static lung volumes, including the residual volume, can be measured by body plethysmography.

\section{The limitations of spirometry}

Any evidence of a restrictive ventilatory impairment calls for further diagnostic evaluation. 
expiratory peak flow is reproducibly, markedly low compared to the $\mathrm{FEV}_{1}$ (Figure $5 b$ ), this may be due to a stenosis of the larger airways (e.g., vocal cord paresis or tumor-induced stenosis of the trachea or main bronchi) (13). Further diagnostic evaluation by a specialist is indicated. The typical clinical features and diagnostic findings associated with the more common causes of dyspnea are summarized in Table 3.

Diseases to be considered in differential diagnosis that can closely resemble COPD in both their clinical manifestations and their spirometric findings include asthma with a fixed obstruction, bronchiectasis, mucoviscidosis, sarcoidosis, silicosis, and tuberculosis (9).

Lastly, one must bear in mind that the symptoms may have more than one cause, e.g., coexistent asthma and COPD (a combination in which the treatment is directed mainly against asthma [e25]), lung cancer and COPD, or left heart failure and COPD. Exercise testing (spiroergometry) may be indicated so that the different contributions of cardiac and bronchopulmonary dysfunction can be told apart (38).

\section{Conclusion}

The widespread availability of electronic spirometers in primary care physicians' practices in Germany provides a good basis for further improvement in the diagnosis of COPD. This will be possible only if physicians are watchful for the risk factors for COPD and its mild initial symptoms and perform pulmonary function testing on all patients with a chronic cough, with or without expectoration. The demonstration of an irreversible airway obstruction confirms the diagnosis. Treatment should then be provided as recommended in the pertinent guidelines (9-12). Treatment decisions are made on the basis of the clinical manifestations, the severity of airway obstruction, and the frequency of exacerbations. A chest X-ray in two planes complements the primary care physician's basic diagnostic evaluation. Any discrepancy between the clinical manifestations and the findings, inadequate cooperation with pulmonary function testing, evidence that a cause other than COPD or a significant comorbidity of COPD may be present, or an unusual constellation of findings should prompt referral of the patient to a pulmonologist for further evaluation. Another reason for referral is to evaluate the indications for treatments such as long-term oxygen therapy for severe COPD.

\section{Acknowledgement}

The authors thank Dipl. Ing. Hans-Jürgen Smith for producing Figures 3 and 5.

\section{Conflict of interest statement}

The authors state that they have no conflict of interest.

Manuscript received on 19 February 2014, revised version accepted on 7 August 2014.

Translated from the original German by Ethan Taub, M.D.

Further information on GME

This article has been certified by the North Rhine Academy for Postgraduate and Continuing Medical Education. Deutsches Ärzteblatt provides certified continuing medical education (CME) in accordance with the requirements of the Medical Associations of the German federal states (Länder). CME points of the Medical Associations can be acquired only through the Internet, not by mail or fax, by the use of the German version of the CME questionnaire. See the following website: cme.aerzteblatt.de.

Participants in the CME program can manage their CME points with their 15-digit "uniform CME number" (einheitliche Fortbildungsnummer, EFN). The EFN must be entered in the appropriate field in the cme.aerzteblatt.de website under "meine Daten" ("my data"), or upon registration. The EFN appears on each participant's CME certificate.

This CME unit can be accessed until 1 March 2015, and earlier CME units until the dates indicated:

- "Chronic and Treatment Resistant Depression" (Issue 45/2014), until 1 February 2015;

- "Physical Examination in Child Sexual Abuse" (Issue 41/2014), until 4 January 2015;

- "Urinalysis in Children and Adolescents" (Issue 37/2014) until 7 December 2014.

\section{Differential diagnosis (3)}

Obstructive ventilatory impairment is a feature not only of COPD, but also of bronchiectasis, mucoviscidosis, sarcoidosis, silicosis, and tuberculosis, among other conditions.
The symptoms may have more than one cause. Common combinations include:

- Asthma and COPD

- Lung cancer and COPD

- Left heart failure and COPD 


\section{REFERENCES}

1. Vos $T$, Flaxman AD, Naghavi M, et al.: Years lived with disability (YLDs) for 1160 sequelae of 289 diseases and injuries 1990-2010: a systematic analysis for the Global Burden of Disease Study 2010. Lancet 2012; 380: 2163-96.

2. Lozano R, Naghavi M, Foreman K, et al.: Global and regional mortality from 235 causes of death for 20 age groups in 1990 and 2010: a systematic analysis for the Global Burden of Disease Study 2010. Lancet 2012; 380: 2095-128.

3. Ciba Foundation Guest Symposium: Terminology, definitions, and classification of chronic pulmonary emphysema and related conditions: a report of the conclusions of a Ciba guest symposium. Thorax 1959; 14: 286-99.

4. Mannino DM: Chronic obstructive pulmonary disease: definition and epidemiology. Respir Care 2003; 48: 1185-93.

5. Tashkin DP. Variations in FEV1 decline over time in chronic obstructive pulmonary disease and its implications. Curr Opin Pulm Med 2013: 19: 116-24.

6. Calverley PMA, Anderson JA, Celli B, et al.: Salmeterol and fluticasone propionate and survival in chronic obstructive pulmonary disease. N Engl J Med 2007; 356: 775-89.

7. Hurst JR, Vestbo J, Anzueto A, et al.: Susceptibility to exacerbation in chronic obstructive pulmonary disease. N Engl J Med 2010; 363: 1128-38

8. Soriano JB, Zielinski J, Price D: Screening for and early detection of chronic obstructive pulmonary disease. Lancet 2009; 374: 721-32.

9. Global Initiative for Chronic Obstructive Lung Disease: Global strategy for diagnosis, management, and prevention of COPD. Updated 2014. www.goldcopd.org/uploads/users/files/ GOLD_Report_2014_Jan23.pdf (last accessed on 7 August 2014)

10. National Clinical Guideline Centre: Chronic obstructive pulmonary disease: management of chronic obstructive pulmonary disease in adults in primary and secondary care. 2010. www. nice.org.uk/guidance/cg101/resources/guidance-chronic-obstructive-pulmonary-disease-pdf (last accessed on 7 August 2014)

11. Qaseem A, Wilt TJ, Weinberger SE, et al.: Diagnosis and management of stable chronic obstructive pulmonary disease: a clinical practice guideline update from the American College of Physicians, American College of Chest Physicians, American Thoracic Society, and European Respiratory Society. Ann Intern Med 2011; 155: 179-91.

12. Vogelmeier $C$, Buhl $R$, Criee $C P$, et al.: Leitlinie der Deutschen Atemwegsliga und der Deutschen Gesellschaft für Pneumologie und Beatmungsmedizin zur Diagnostik und Therapie von Patienten mit chronisch obstruktiver Bronchitis und Lungenemphysem (COPD). Pneumologie 2007; 61: e1-e40.

13. Hyatt RE, Scanlon PD, Nakamura M: Interpretation of pulmonary function tests: a practical guide. $3^{\text {rd }}$ edition. Philadelphia: Wolters Kluwer; 2008.

14. Gibson GJ: Clinical tests of respiratory function. $3^{\text {rd }}$ edition. London: Hodder Arnold; 2009.
15. Buist AS, McBurnie MA, Vollmer WM, et al.: International variation in the prevalence of COPD (the BOLD study): a populationbased prevalence study. Lancet 2007; 370: 741-50.

16. Leung JM, Sin DD: COPD in never smokers: prognosis unveiled. Lancet Respir Med 2013; 1: 502-4.

17. Lamprecht B, McBurnie MA, Vollmer WM, et al.: COPD in never smokers: results from the population-based burden of obstructive lung disease study. Chest 2011; 139: 752-63.

18. Thomsen M, Nordestgaard BG, Vestbo J, Lange P: Characteristics and outcomes of chronic obstructive pulmonary disease in never smokers in Denmark: a prospective population study. Lancet Respir Med 2013; 1: 543-50.

19. Salvi SS, Barnes PJ: Chronic obstructive pulmonary disease in non-smokers. Lancet 2009; 374: 733-43.

20. Hogg JC, Chu F, Utokaparch S, et al.: The nature of small-airway obstruction in chronic obstructive pulmonary disease. N Engl J Med 2004; 350: 2645-53.

21. Kessler R, Partridge MR, Miravitlles M, et al.: Symptom variability in patients with severe COPD: a pan-European crosssectional study. Eur Respir J 2011; 37: 264-72.

22. Van Remoortel H, Hornikx M, Demeyer H, et al.: Daily physical activity in subjects with newly diagnosed COPD. Thorax 2013; 68: 962-3.

23. Holleman D, Simel D: Does the clinical examination predict airflow limitation? JAMA 1995; 273: 313-9.

24. Littmann ${ }^{\circledR} 3$ M. Physiological \& pathological breath sounds. www.youtube.com/watch?v=080C7EiqBKQ\&feature $=k p$ (last accessed on 7 August 2014)

25. Bohadana A, Izbicki G, Kraman SS: Fundamentals of lung auscultation. N Engl J Med 2014; 370: 744-51.

26. Marciniuk D, Hernandez P, Balter M, et al.: Alpha-1-antitrypsin deficiency targeted testing and augmentation therapy: A Canadian Thoracic Society clinical practice guideline. Can Respir J 2012; 19: 109-16.

27. Criée C-P, Berdel D, Heise D, et al.: Empfehlungen der Deutschen Atemwegsliga zur Spirometrie. 2006. www.atemwegsli ga.de/empfehlungen-positionspapiere.html (last accessed on 7 August 2014)

28. Global Initiative for Chronic Obstructive Lung Disease (GOLD) Spirometry for health care providers. 2010. www. goldcopd.org/ uploads/users/files/GOLD_Spirometry_2010.pdf (last accessed on 7 August 2014)

29. Pellegrino R, Viegi G, Brusasco V, et al.: Interpretative strategies for lung function tests. Eur Respir J 2005; 26: 948-68.

30. Swanney MP, Ruppel G, Enright PL, et al.: Using the lower limit of normal for the FEV1/FVC ratio reduces the misclassification of airway obstruction. Thorax 2008; 63: 1046-51.

31. Cerveri I, Corsico AG, Accordini S, et al.: Underestimation of airflow obstruction among young adults using FEV1/FVC $<70 \%$ as a fixed cut-off: a longitudinal evaluation of clinical and functional outcomes. Thorax 2008; 63: 1040-5. 
32. Quanjer PH, Stanojevic S, Cole TJ, et al.: Multi-ethnic reference values for spirometry for the 3-95-yr age range: the global lung function 2012 equations. Eur Respir J 2012; 40: 1324-43.

33. Bourbeau J, Tan WC, Benedetti A, et al.: Canadian Cohort Obstructive Lung Disease (CanCOLD): Fulfilling the need for Iongitudinal observational studies in COPD. COPD: J Chron Obstruct Pulmon Dis 2014; 11: 125-32.

34. Thomas M, Decramer M, O'Donnell D: No room to breathe: the importance of lung hyperinflation in COPD. Prim Care Respir J 2013; 22: 101-11.

35. Celli BR, Cote CG, Marin JM, et al.: The body-mass index, airflow obstruction, dyspnea, and exercise capacity index in chronic obstructive pulmonary disease. N Engl J Med 2004; 350: 1005-12.

36. Agusti AA., Hurd S, Jones P, et al.: FAQs about the GOLD 2011 assessment proposal of COPD: a comparative analysis of four different cohorts. Eur Respir J 2013; 42: 1391-401.

37. Miller MR, Hankinson J, Brusasco V, et al.: Standardisation of spirometry. Eur Respir J 2005; 26: 319-38.
38. Peters SP. When the chief complaint is (or should be) dyspnea in adults. J Allergy Clin Immunol Pract 2013; 1: 129-36.

39. Wielpütz MO, Heußel CP, Herth FJF, Kauczor H-U: Radiological diagnosis in lung disease: factoring treatment options into the choice of diagnostic modality. Dtsch Arztebl International 2014; 111: 181-7.

40. Kroegel C, Costabel U: Klinische Pneumologie: das Referenzwerk für Klinik und Praxis. Stuttgart: Thieme; 2014.

\section{Corresponding author}

Dr. med. Rainer Burkhardt

Kassenärztliche Vereinigung Niedersachsen

Bezirksstelle Oldenburg

Huntestr. 14

26135 Oldenburg, Germany

rainer.burkhardt@kvn.de

For eReferences please refer to:

www.aerzteblatt-international.de/ref4914

esupplement:

www.aerzteblatt-international.de/14m0834 
Question 1

Which of the following factors makes the prevalence of COPD hard to estimate epidemiologically?
a) the declining number of smokers
b) variable diagnostic criteria across studies
c) recent demographic trends
d) increasing participation rates in clinical trials
e) the many patients whose pulmonary function has
normalized due to appropriate treatment

\section{Question 2}

Which of the following is the most important risk factor for COPD in Germany?
a) cholesterol
b) overweight
c) cigarette smoking
d) glucose intolerance
e) environmental pollution

\section{Question 3}

A 50-year-old male smoker comes for follow-up after an episode of bronchitis with dyspnea. The heart and lungs are normal to auscultation. In the past two years, he has had more frequent episodes of bronchitis than before. Which test should be done first in the further work-up? a) echocardiography

b) blood-gas analysis

c) immunglobulin subclass measurement

d) spirometry

e) HIV screening test

\section{Question 4}

Which of the following symptoms in a smoker can be considered evidence of COPD?
a) polyuria
b) memory disturbances
c) exertional dyspnea
d) allergies
e) recurrent diarrhea

\section{Question 5}

What abnormality of speech may be a sign of dyspnea due to COPD?
a) dyslalia
b) dysphasia
c) sigmatism
d) interrupted flow of speech
e) stuttering

Question 6

Which of the following is a typical physical finding in a patient with COPD?
a) peripheral edema
b) in the early stage, the physical examination is often completely normal
c) dullness of the lung fields to percussion
d) pallor of the skin
e) a diastolic heart murmur

Question 7

What is the most sensitive test for airway obstruction?
a) ECG at rest
b) chest x-ray in expiration
c) duplex sonography
d) spirometry with forced expiration
e) pulse oximetry

\section{Question 8}
What does "FEV ${ }_{1}$ " stand for?
a) the average volume of gas moved in one minute of normal breathing
b) the total volume expired in a forced expiration
c) the maximal volume expired in one minute by forced expiration
d) the maximal volume expired in one second by forced expiration
e) the maximal volume that can be additionally expired after a normal expiration

\section{Question 9}

In a 62-year-old female smoker with increased fatigability, spirometry reveals a Tiffeneau Index of 0.58 and an $\mathrm{FEV}_{1}$ that is $65 \%$ of the reference value. Her $\mathrm{FEV}_{1}$ remains markedly low in a bronchodilator reversibility test. What is the most likely diagnosis?
a) interstitial lung disease with a restrictive ventilation disturbance
b) COPD
c) bronchial asthma
d) left-heart failure
e) a combined ventilation disturbance

Question 10

A 45-year-old female nonsmoker with a history of hay fever and episodic dyspnea complains of shortness of breath in the setting of an acute airway infection. Auscultation reveals wheezing. The $\mathrm{FEV}_{1}$ is $55 \%$ of the reference value, and the Tiffeneau Index is $\mathbf{0 . 6}$. Both of these values become normal during bronchodilator reversibility testing. What is the most likely diagnosis?
a) COPD with GOLD 2 airway obstruction
b) COPD with GOLD 4 airway obstruction
c) bronchial asthma
d) interstitial lung disease
e) congestive heart failure 


\title{
The Diagnosis of Chronic Obstructive Pulmonary Disease
}

\author{
Rainer Burkhardt, Wulf Pankow
}

\section{EREFERENCES}

e1. Gesundheitsberichterstattung des Bundes: Todesursachenstatistik, Statistik der Gestorbenen, Todesursache, Sterbefälle. 2014. www.gbe-bund.de/glossar/Todesursachenstatistik.html (last accessed on 7 August 2014)

e2. Casanova C, Aguirre-Jaíme A, Torres JP de, et al.: Longitudinal assessment in COPD patients: multidimensional variability and outcomes. Eur Respir J 2014; 43: 745-53.

e3. Advisory Council for the Concerted Action in Health Care: Appropriateness and efficiency. Volume III: Overuse, underuse and misuse. 2001. www.svr-gesundheit.de/fileadmin/user_upload/Gu tachten/2000-2001/Kurzf-engl01.pdf (last accessed on 7 August 2014)

e4. Abholz H, Gillissen A, Magnussen H, et al.: Nationale Versorgungsleitlinie COPD Langfassung Version 1.9, basierend auf der Fassung vom Februar 2006. 2012. www.versorgungsleitlinien.de/ themen/copd/pdf/nvl-copd-lang-1.9.pdf (last accessed on 7 August 2014)

e5. Geldmacher H, Biller H, Herbst A, et al.: Die Prävalenz der chronisch obstruktiven Lungenerkrankung (COPD) in Deutschland. Ergebnisse der BOLD-Studie. Dtsch Med Wochenschr 2008; 133: 2609-14.

e6. Gingter C, Wilm S, Abholz H-H: Is COPD a rare disease? Prevalence and identification rates in smokers aged 40 years and over within general practice in Germany. Fam Pract 2009; 26: 3-9.

e7. Gläser S, Schäper C, Obst A, et al.: Impact of different definitions of airflow limitation on the prevalence of chronic obstructive pulmonary disease in the general population. Respiration 2010; 80: 292-300.

e8. Lampert T, Lippe E von der, Müters S: Verbreitung des Rauchens in der Erwachsenenbevölkerung in Deutschland. Bundesgesundheitsblatt - Gesundheitsforschung - Gesundheitsschutz 2013; 56: 802-8.

e9. Løkke A, Lange P, Scharling H, Fabricius P, Vestbo J: Developing COPD: a 25 year follow up study of the general population. Thorax 2006; 61: 935-9.

e10. Behrendt CE: Mild and moderate-to-severe COPD in nonsmokers: distinct demographic profiles. Chest 2005; 128: 1239-44.

e11. Schikowski T, Mills IC, Anderson HR, et al.: Ambient air pollution: a cause of COPD? Eur Respir J 2014; 43: 250-63.

e12. Mapel DW, Dalal AA, Blanchette CM, Petersen H, Ferguson GT: Severity of COPD at initial spirometry-confirmed diagnosis: data from medical charts and administrative claims. Int J Chron Obstruct Pulmon Dis 2011; 6: 573-81.

e13. Oshaug K, Halvorsen PA, Melbye H: Should chest examination be reinstated in the early diagnosis of chronic obstructive pulmonary disease? Int J Chron Obstruct Pulmon Dis 2013; 8: 369-77.

e14. Simel D: Update: chronic obstructive airways disease. In: DL Simel, D. Rennie and SA Keitz: The rational clinical examination: evidence-based clinical diagnosis. 159-62. New York: McGrawHill; 2008.

e15. Fabricius P, Løkke A, Marott JL, Vestbo J, Lange P: Prevalence of COPD in Copenhagen. Respir Med 2011; 105: 410-7. e16. Lam DCL, Hui CKM, Ip MSM: Issues in pulmonary function testing for the screening and diagnosis of chronic obstructive pulmonary disease. Curr Opin Pulm Med 2012; 18: 104-11.

e17. Irizar-Aramburu M, Martinez-Eizaguirre J, Pacheco-Bravo P, et al.: Effectiveness of spirometry as a motivational tool for smoking cessation: a clinical trial, the ESPIMOAT study. BMC Family Practice 2013; 14: 185

e18. Murphy DE, Panos RJ: Diagnosis of COPD and clinical course in patients with unrecognized airflow limitation. Int J Chron Obstruct Pulmon Dis 2013; 8: 199-208.

e19. Herpel LB, Kanner RE, Lee SM, et al.: Variability of spirometry in chronic obstructive pulmonary disease. Results from two clinical trials. Am J Respir Crit Care Med 2006; 173: 1106-13.

e20. Miller MR: Getting the diagnosis of chronic obstructive pulmonary disease correct. Am J Respir Crit Care Med 2014; 189: 228-9.

e21. Stanojevic S, Quanjer P, Miller MR, Stocks J: The Global Lung Function Initiative: dispelling some myths of lung function test interpretation. Breathe 2013; 9: 462-74.

e22. Loring SH, Garcia-Jacques M, Malhotra A: Pulmonary characteristics in COPD and mechanisms of increased work of breathing. J Appl Physiol 2009; 107: 309-14.

e23. Price DB, Yawn BP, Jones RCM: Improving the differential diagnosis of chronic obstructive pulmonary disease in primary care. Mayo Clin Proc 2010; 85: 1122-9.

e24. Miravitlles M, Andreu I, Romero Y, Sitjar S, Altés A, Anton E: Difficulties in differential diagnosis of COPD and asthma in primary care. Br J Gen Pract 2012; 62: e68-e75.

e25. Global Initiative for Asthma. Global Strategy for Asthma Management and Prevention 2014. www.ginasthma.org/documents/4 (last accessed on 7 August 2014)

e26. Tuder RM, Petrache I: Pathogenesis of chronic obstructive pulmonary disease. J Clin Invest 2012; 122: 2749-55.

e27. Köhler D, Schönhofer B, Voshaar T: Pneumologie: Ein Leitfaden für rationales Handeln in Klinik und Praxis. Stuttgart: Thieme; 2010.

e28. European Respiratory Society: European lung white book 2013. www.erswhitebook.org/ (last accessed on 7 August 2014)

e29. Coates A, Graham B, McFadden R, et al.: Spirometry in primary care. Can Respir J 2013; 20: 13-21.

e30. Townsend MC, Hankinson JL, Lindesmith LA, Slivka WA, Stiver G, Ayres GT: Is my lung function really that good? Flow-type spirometer problems that elevate test results. Chest 2004; 125: 1902-9.

e31. Enright PL: Should we keep pushing for a spirometer in every doctor's office? Respir Care 2012; 57: 146-53.

e32. Quanjer PH, Pretto JJ, Brazzale DJ, Boros PW: Grading the severity of airways obstruction: new wine in new bottles. Eur Respir $J$ 2014; 43: 505-12.

e33. Quanjer PH, Weiner DJ, Pretto JJ, Brazzale DJ, Boros PW: Measurement of FEF25-75\% and FEF75\% does not contribute to clinical decision making. Eur Respir J 2014; 43: 1051-58. 


\title{
The Diagnosis of Chronic Obstructive Pulmonary Disease
}

\author{
Rainer Burkhardt, Wulf Pankow
}

\section{The spirometric examination}

The calibration of all spirometers should be checked and verified with a 3-liter calibrating injection at least once on each examining day, before the first patient is tested (37). The tolerance limit for deviations from the applied volume is $3.5 \%$ (e29). Such testing should also be carried out whenever the measured values seem implausible. Artefactually high values may be due to material deposited in the flow sensor (pneumotachograph) (e30). Volume errors due to fluctuations of air temperature and humidity must be corrected by entering the current environmental conditions into the system.

The spirometric examination (37) consists of maneuvers that involve breathing at rest followed by a forced expiration maneuver. Once accommodated to the nose clamp and to oral breathing through the mouthpiece and filter, the patient is asked to perform a maximal, temporally unlimited expiration until volume tracing in the spirogram reaches a plateau. The patient is then instructed to take a rapid, maximal inspiration. The inspired volume is the IVC (inspiratory vital capacity). Right after this maximal inspiration, without any pause in between, there follows a maximally rapid (forced) and complete (sustained) expiration, under the enthusiastic encouragement of the testing personnel. Six seconds usually suffice for this maneuver, but it may take much longer in persons with COPD because of the increased limitation of expiratory flow. The test should be stopped if prolonged expiration is too much of a strain for the patient, or if no plateau has been reached in 15 seconds.

The graph of volume against time over the course of this maneuver is called a spirogram (eFigure 1). The

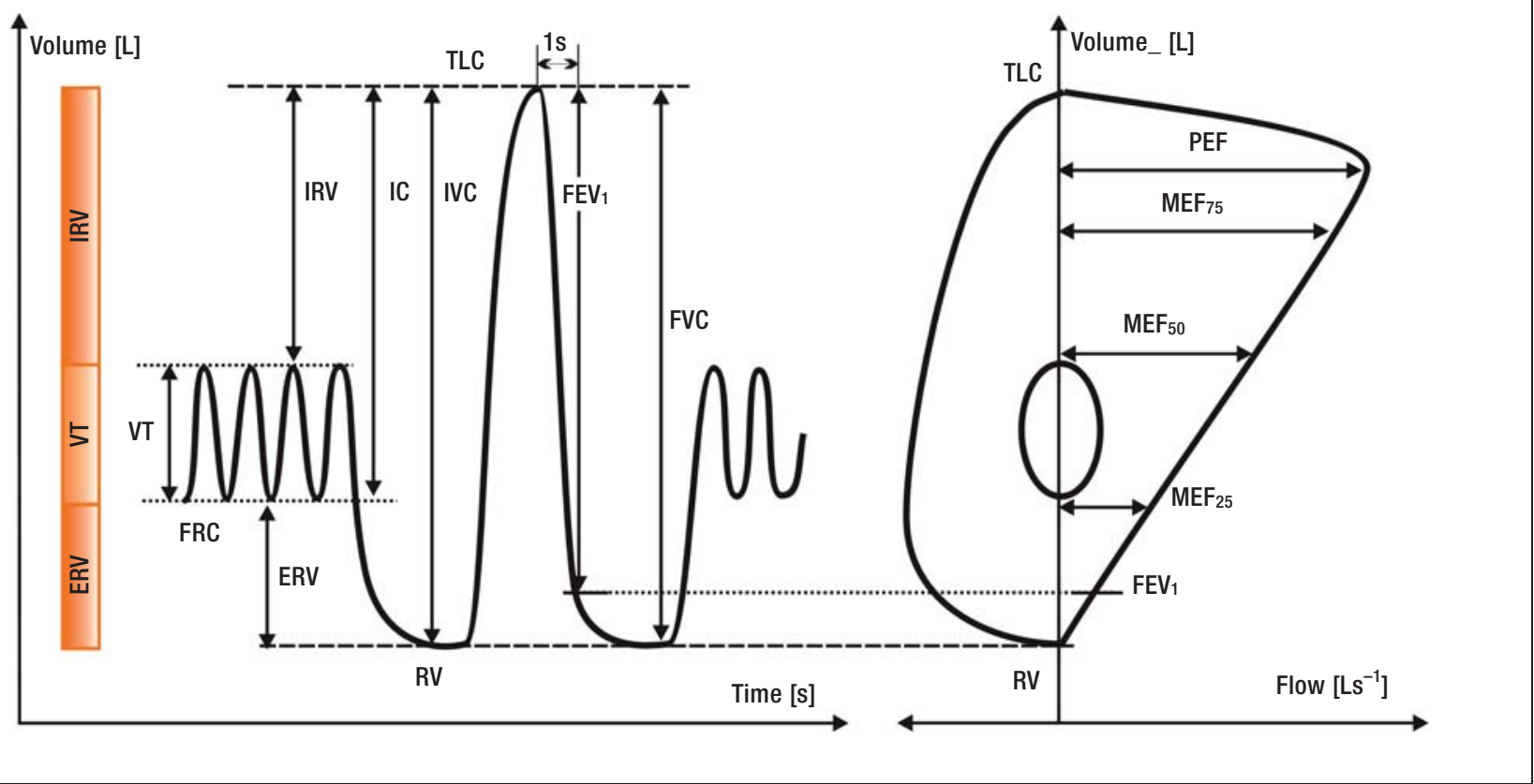

Volume and flow relationships in a standardized spirographic test with a bar chart of volume parameters (left) and a flow-volume curve for the forced expiration meneuver (right), displayed on a common volume axis; normal findings. ERV, expiratory reserve volume; VT, tidal volume; IRV, inspiratory reserve volume; FRC, functional residual capacity; IC, inspiratory capacity; $\mathrm{FEV}_{1}$, forced expiratory volume in one second; FVC, forced expiratory vital capacity; TLC, total lung capacity; $\mathrm{PEF}$, peak expiratory flow; $\mathrm{MEF}_{25}$, maximal expiratory flow with $25 \%$ of $\mathrm{FVC}$ remaining to be expired; $\mathrm{MEF}_{50}$, maximal expiratory flow at half of FVC; $\mathrm{MEF}_{75}$, maximal expiratory flow with $75 \%$ of $\mathrm{FVC}$ remaining to be expired. The parameters $\mathrm{MEF}_{50}$ and $\mathrm{MEF}_{25}$ for the maximal expiratory flow in the middle and terminal portions of expiration, which are derived from the flow-volume curve, vary too widely among normal persons to be of diagnostic value (e33). 


\section{GGRAFIK 2}

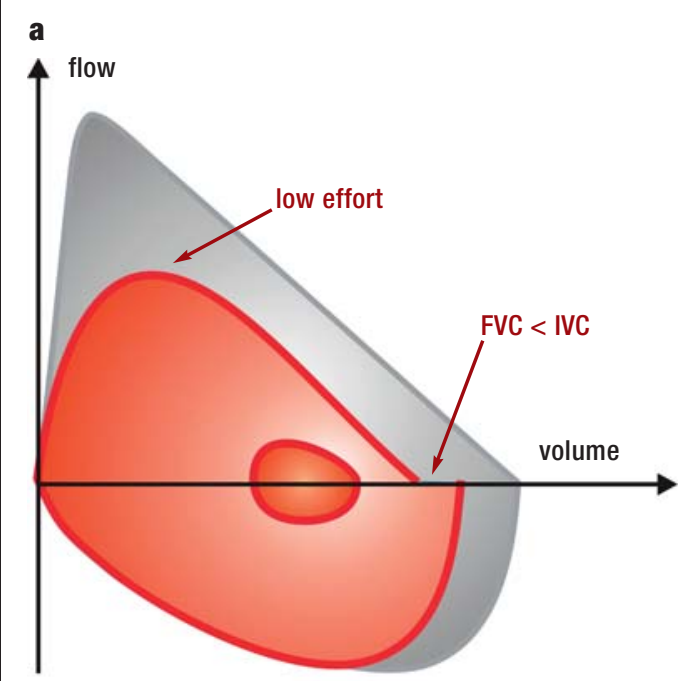

b

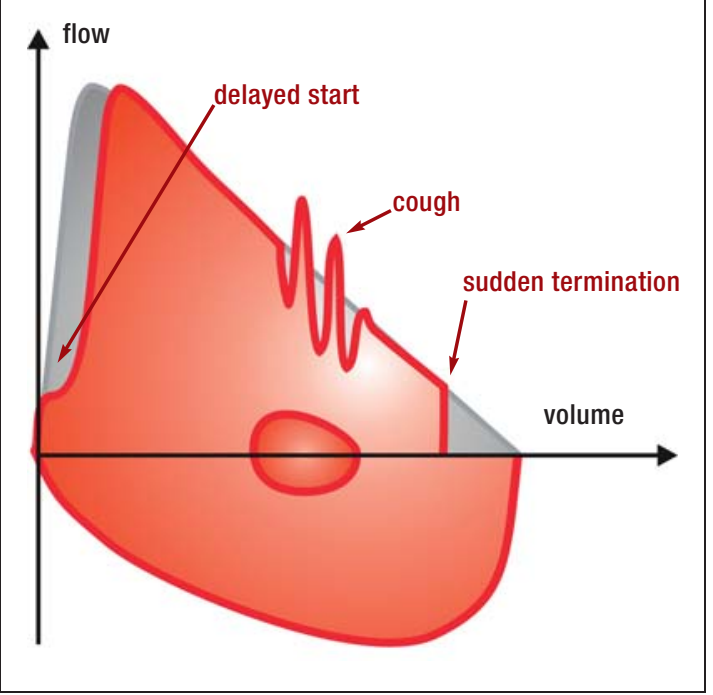

spirogram is the source of the partial lung volumes known as IVC, tidal volume (VT), expiratory reserve volume (ERV), inspiratory reserve volume (IRV), and inspiratory capacity (IC). Forced expiration permits measurement of the $\mathrm{FEV}_{1}$ (forced expiratory capacity in one second) and FVC (forced expiratory vital capacity). Maximal inspiration and forced expiration are depicted graphically as a flow-volume curve. The patient's performance of respiratory maneuvers is easiest to monitor and control if the spirogram and flow-volume curve are displayed on a screen in real time (37).

The measured parameters permit an objective characterization of lung function if the patient has taken a maximal inspiration to TLC (total lung capacity) and if the expiratory effort was sufficient to generate maximum flow under the individual limitations present in health or disease. The two most successful attempts should yield nearly superimposable curves (29).
Errors in the performance of spirometry that can be recognized on the flow-volume curve:

a) low effort with flat course of maximal flow; FVC $<$ IVC because of premature cessation of expiration, air leak of the mouthpiece, or improper zero level adjustment of the spirometer; in patients with severe obstruction, FVC < IVC may also be due to the expiratory collapse of peripheral airways;

b) delayed start of expiration, coughing during forced expiration, and sudden termination of expiration.

FVC, forced expiratory vital capacity; IVC, inspiratory vital capacity. Diagram, H.-J. Smith

\section{Quality assessment}

The measured $\mathrm{FEV}_{1}$ value can be altered by the temporal delay (inevitable, to some extent) until peak expiratory flow (PEF) is reached. To eliminate this effect, the time of onset of expiration for measuring purposes is determined by a mathematical extrapolation, as if the expiration had been performed with peak flow from the beginning. The volume of air already expired up to this moment is called the extrapolation volume (37).

The following criteria characterize a successful forced expiration maneuver (28):

- A maximal inspiration was performed.

- The forced expiration began immediately after the end of the maximal inspiration, as can be seen from the minimal duration of the inspiratory plateau on the spirogram.

- Peak expiratory flow (PEF) was reached within $120 \mathrm{~ms}$ (steep initial portion of flow-volume curve).

- Extrapolation volume $\leq 150 \mathrm{~mL}$ (or $5 \%$ of FVC, if $\mathrm{FVC}>3 \mathrm{~L}$ ).

- A smooth curve of volume against time (no coughing during the maneuver, no interruption of forced expiratory flow by additional inspiration, glottis closure, or hesitation).

- No premature termination of the maneuver (plateau attainment: volume change $<25 \mathrm{~mL}$ in the last second of visibly sustained expiratory effort).

- No air leak in the mouthpiece or filter.

- No obstruction of the mouthpiece by the tongue or a dental prosthesis.

The documentation of any confounding factors that may arise during testing (insofar as they are not automatically detected by the apparatus) further enhances the validity of the interpretation. It is also very important for the physician interpreting the test findings to report back to the testing personnel his or her assessment of the quality of testing (e31).

An illustrative flow-volume curve containing various indications of faulty test performance is shown in eFigure 2. Even the less than fully successful attempts can suffice for a determination of the $\mathrm{FEV}_{1}$, as long as the expiration was begun without delay and the patient did not cough during the first second.

The interpretation of findings can be made more reliable through the use of the new norm tables that take 
account of the patient's ethnic origin (e32). Software for the calculation of the new norms and threshold values can be downloaded free of charge from the website www.lungfunction.org.

This appendix was prepared with the assistance of Dipl. Ing.Hans-Jürgen Smith (CareFusion Germany 234 GmbH, Höchberg). 